\title{
Dangers of Treatment of Status Epilepticus with Diazepam
}

\author{
D. S. BELL,* M.B., B.SC., M.A.N.Z.C.P.
}

Brit. med.F., 1969, 1, 159-161

\begin{abstract}
Summary : The results of treatment of 25 patients admitted from psychiatric institutions indicate that diazepam is the drug of first choice in the treatment of status epilepticus. The dangers of treatment appeared to result from combined use with other drugs. Respiratory depression occurred in one patient and hypotension in five patients, all of whom had been given intramuscular phenobarbitone in addition to intravenous diazepam. The two serious cases of hypotension had also been given parenteral paraldehyde.
\end{abstract}

\section{Introduction}

Previous reports which have established that parenterally administered diazepam (Valium) is effective in the treatment of status epilepticus also indicate that diazepam does not have severe depressant effects on the central nervous system, nor any serious side-effects. The absence of ill-effects is unusual for a potent drug, whereas the failure to recognize these has been common enough in the early experience of the use of many drugs.

\section{Case Material}

The case material consists of a consecutive series of 25 patients (13 male and 12 female) with status epilepticus transferred during a period of two years, in most cases as emergencies, from psychiatric hospitals to a neuropsychiatric unit. The group included all cases refractory to conventional methods of treatment.

The mean age of the patients was 39 (range 7 to 69) years ; 22 were aged 20 or more. The mean duration of the epilepsy was eight years (range 2 months to 32 years). During the episodes of status epilepticus 14 patients did not regain consciousness between seizures and nine only partially regained consciousness. The only two subjects without impairment of consciousness had focal motor seizures-epilepsia partialis continua in one and Jacksonian epilepsy in the other.

The initial dose of diazepam was given intravenously over at least five minutes, with particular attention to blood pressure changes. In 17 cases the effects of diazepam were monitored with the electroencephalograph. In those cases requiring repeated injections the rate of administration was assessed from the response to $10 \mathrm{mg}$. When the seizures were arrested fairly readily the subsequent dose of diazepam was given intramuscularly ; more refractory cases received intermittent intravenous injections, and in cases particularly difficult to control the drug was given continuously in an intravenous drip.

The patient's normal anticonvulsant medication was continued during treatment with diazepam. Phenobarbitone and phenytoin were given intramuscularly when there was a poor or limited response to diazepam, and in two cases the supplementary treatment included intramuscular paraldehyde.

\section{Results}

The initial dose of diazepam, which in individual cases ranged from 2.5 to $40 \mathrm{mg}$., brought prompt arrest of the seizures of

* Psychiatrist-in-Charge, Psychiatric Research Unit, Callan Park Hospital, Rozelle, N.S.W. 2039, Australia.
11 patients. Another five had an almost equally good responsein one the continuous seizure activity ceased eight minutes after the slow administration of $50 \mathrm{mg}$. of diazepam, and in the other four cases occasional fits persisted for some hours after the initial dose had arrested the continuous seizure activity. An incomplete but useful control of seizure activity was obtained for two patients and seven had a poor response.

Four patients had more than one episode treated with diazepam, and in one case the second episode, which occurred in the terminal phase of the patient's illness, was not controlled as well as the first.

\section{Complications}

One patient died four days after her second episode of status epilepticus. She had been moribund for some weeks and the epilepsy appeared to be a terminal phenomenon. In another case the status epilepticus was the first clinical indication of a severe and progressive renal insufficiency that resulted in death 12 days later. One patient (Case 6), discussed in detail below, died after a period of hypotension which may have been the result of treatment. There were no other deaths within four weeks of treatment with diazepam.

Respiratory depression was encountered on only one occasion. Though only a very small dose was needed to arrest the patient's seizures-that is, $2.5 \mathrm{mg}$.-Cheynes-Stokes respiration appeared and persisted for about one hour. The patient did not have respiratory depression in a later episode, which was treated with considerably larger doses.

Hypotension was the only potentially serious complication of treatment with diazepam observed. It was encountered in six cases.

Case 1.-Treatment with $2.5 \mathrm{mg}$. of diazepam precipitated the episode of Cheynes-Stokes respiration described above and a temporary fall in blood pressure from $130 / 90$ to $105 / 70 \mathrm{~mm}$. $\mathrm{Hg}$, which was lower than any level found in the regular two-hourly recordings kept for the preceding two months. In a second episode 19 days later $100 \mathrm{mg}$. of phenobarbitone intramuscularly had no apparent effect, but $40 \mathrm{mg}$. of diazepam arrested the status for 30 minutes. The blood pressure dropped to $98 / 60$, slowly rising to $130 / 85$ in the subsequent nine hours. When treatment with diazepam was resumed the blood pressure fell to 90/60. A slower rate of administration, resulting in only a partial control of the seizures, prevented any further fall in blood pressure.

Case 2.-This patient had been given $200 \mathrm{mg}$. of phenobarbitone intramuscularly without any apparent effect on the continuous focal motor seizure. After the slow administration of $50 \mathrm{mg}$. of diazepam the blood pressure dropped from $180 / 100$ to $120 / 100 \mathrm{~mm}$. $\mathrm{Hg}$, recovering in three hours to $150 / 100$.

Case 3.-The seizures were arrested by six separate injections of $10 \mathrm{mg}$. given over a period of three and a quarter hours, but the blood pressure dropped from $130 / 80$ to $90 / 50 \mathrm{~mm}$. $\mathrm{Hg}$. Treatment with metaraminol $1 \mathrm{mg}$. intravenously and $5 \mathrm{mg}$. intramuscularly was followed by a rise to $120 / 70$.

Case 4.-Treatment with intramuscular phenobarbitone and $40 \mathrm{mg}$. of diazepam intravenously produced only partial control of the seizures and a fall in the blood pressure from 140/96 to $106 / 78 \mathrm{~mm}$. Hg. No more diazepam was given for 11 hours and the blood pressure recovered. An intravenous drip containing $30 \mathrm{mg}$. of diazepam per litre achieved effective control of the seizures, but after 13 hours the blood pressure dropped to $98 / 70$. A slower rate of administration allowed the blood pressure to recover to $134 / 90$ in the next five hours. 
Case 5.-This patient was admitted on the third day of status epilepticus uncontrolled by treatment with intramuscular phenobarbitone $200 \mathrm{mg}$. twice daily and paraldehyde $10 \mathrm{ml}$. four-hourly. Over a period of six hours she was given $100 \mathrm{mg}$. of diazepam intravenously and her blood pressure slowly fell from 110/80 to $100 / 50 \mathrm{~mm}$. Hg. Shortly thereafter the systolic pressure fell precipitately to $66 \mathrm{~mm}$. and the diastolic pressure could not be recorded. A rapid infusion of intravenous fluid and $100 \mathrm{ml}$. of concentrated albumin allowed a recovery to $100 / 80$ within 15 minutes, The seizures recurred and a further intravenous injection of $20 \mathrm{mg}$. of diazepam was followed by a drop in systolic pressure to $68 \mathrm{~mm}$. the diastolic pressure once more being unrecordable. The blood pressure rose to $90 / 70$ after another rapid infusion of fluids and albumin. Treatment with intravenous diazepam was resumed cautiously one and a half days after the episode of hypotension, but only at a rate that produced limited control of the seizures.

Case 6.-This case of severe hypotension had a fatal outcome. The patient had been controlled partially with diazepam in a previous episode. The fatal episode occurred two months later. In the first 24 hours the patient was given $10 \mathrm{ml}$. of paraldehyde intramuscularly and $130 \mathrm{mg}$. of diazepam intravenously, the blood pressure dropping from $130 / 90$ to $100 / 70 \mathrm{~mm}$. $\mathrm{Hg}$. In the next 10 hours she was given a further $680 \mathrm{mg}$. of diazepam intravenously, $200 \mathrm{mg}$. of phenobarbitone and $250 \mathrm{mg}$. of phenytoin intramuscularly, and her usual oral dose of sulthiame. The blood pressure continued to fall until ultimately it could not be recorded. The seizures ceased but the patient did not regain consciousness. Intravenous fluids, intravenous metaraminol, antibiotics, and intravenous hydrocortisone were given but did not reverse the hypotension, and the patient died 32 hours after the last dose of diazepam. Severe inhalation pneumonia was verified at necropsy.

\section{Discussion}

This group of patients is representative of the more difficult treatment problems of status epilepticus that arise in patients admitted from psychiatric institutions. Sixteen of the 25 patients responded excellently to diazepam and a useful though incomplete control was obtained for two others. In the seven cases in which control of the seizure activity was inadequate the results of treatment with other anticonvulsants were no better. These results are consistent with those in other series, and indicate that diazepam is effective in the control of many cases of status epilepticus and probably should be the treatment of first choice, except perhaps in the case of alcohol withdrawal seizures, which respond well to parenteral paraldehyde (Golbert et al., 1967).

The depressant effects of diazepam on the central nervous system provided the only hazards of treatment. A parallel may be found in the respiratory and hypotensive effects of diazepam shown in experimental animals. Intravenous diazepam produces a moderate degree of hypoventilation in mice (Maspoli, 1967). In the dog rapid injection produces a dose-dependent decrease in blood pressure (Brassier et al., 1966). Chai and Wang (1966) have shown in the cat that, in addition to a less significant peripheral vasodilator effect, the intravenous administration of diazepam lowers the blood pressure by depressing the hypothalamic and medullary responses.

Respiratory depression was seen only once and did not present any problem of management. Gastaut et al. (1965), who claimed that diazepam has no depressant effects, observed respiratory depression in one case. Prensky et al. (1967) observed respiratory depression in three cases and suggested that it was a consequence of a synergism with barbiturates. A case of respiratory depression reported by Lalji et al. (1967) also occurred after treatment with both intravenous diazepam and barbiturate, and the case observed in our own series had been given a barbiturate parenterally.

Hypotension was a relatively frequent complication of treatment in this series. Four patients had moderate falls of blood pressure. In each case the hypotension occurred within an hour of the intravenous administration of diazepam, and slow recovery followed in the subsequent few hours after the diazepam was suspended. In two cases this sequence of events occurred more than once in the treatment of a single episode of prolonged seizure activity. Clinically the cases were comparable to the rest of the series in respect of the range of disorders and severity of seizures. All were adults.

The two patients who became hypotensive to a serious degree had some factors in common. Both received relatively large doses and both had inhalation pneumonia. They were given other drugs as well, receiving paraldehyde and phenobarbitone intramuscularly.

The factor in common for all the cases of hypotension in this series was that the patients had been given phenobarbitone intramuscularly in conjunction with diazepam. Only seven of the other 22 episodes in the series had been treated with this combination. The relationship is statistically significant (Fisher exact probability test, $\mathrm{P}<0.02$, one-tailed).

Hypotension does not seem to have occurred in the course of the extensive use of diazepam in the treatment of tetanus, even though barbiturates were also given in many cases (FemiPearse, 1966 ; Hendrickse and Sherman, 1966). However, it has been reported in cases of status epilepticus treated with diazepam. Parsonage and Norris (1967) reported hypotension to have preceded death in one of their nine cases, but did not believe the fall in blood pressure was due to diazepam. Sawyer et al. (1968) observed hypotension in one case in which parenteral barbiturate had also been given. Prensky et al. (1967) noted hypotension in three cases in their tables, though they referred to only two cases in their text. One of these had been given parenteral barbiturates in addition to diazepam. As in our own scries, all the patients who became hypotensive were adults.

If allowance is made for the high proportion of children in the series reported to date, the incidence of hypotension as a complication of diazepam treatment of status epilepticus in the adult assumes greater significance. The seven reported cases of serious hypotension, including two in the present series, were observed in four series totalling 70 adult subjects. Five of the seven patients had been treated with other drugs as well, in four cases the drugs being parenteral barbiturates. Furthermore, it would appear that in other series of adults in which hypotension was not observed diazepam was usually used alone in treating the status epilepticus.

The dangers of overzealous and excessive treatment in the management of status epilepticus have been emphasized in recent years. Lombroso (1966) pointed out that the patient in status epilepticus is peculiarly susceptible to the depressant effects of drugs. He found that almost a quarter of a group of children who had succumbed in status epilepticus had cardiac or respiratory arrest, or both, shortly after the intravenous administration of a hypnotic agent. The unwise pursuit of an ideal in which the seizures are completely arrested may result in the administration of one drug after another, adding the risk of largely unknown synergistic effects. In fact, some cases that are partly refractory to treatment make satisfactory progress if allowed to continue with partial or modified seizures until the episode ceases in its own time (Sawyer et al., 1968).

The conclusion that diazepam is the drug of first choice in the treatment of status epilepticus clearly must be qualified. It should not be taken to imply that the effective anticonvulsants can be used in order of choice with impunity. The danger attendant on a synergistic action of barbiturates with diazepam may eventually be shown to exist for a variety of other drugs as well.

I am grateful to Dr. A. K. Lethlean and Mr. R. S. Gye for permission to include patients under their care in this report, to Sister L. Rich for her assistance in collating the nursing and clinical records, to Professor L. G. Kiloh for editing the manuscript, and 
to Mr. R. J. Kirkby for the statistical calculations. The Director, Division of Establishments, Department of Public Health of New South Wales, has given permission to publish this paper.

\section{REFERENCES}

Brassier, J., Eben-Moussi, E., Allain, P., and Van Den Driessche, J. (1966). Thérapie, 21, 379.

Chai, C. Y., and Wang, S. C. (1966). F. Pharmacol. exp. Ther., 154, 271. Femi-Pearse, D. (1966). Brit. med. $\mathcal{F}$., 2, 862.

Gastaut, H., Naquet, R., Poiré, R., and Tassinari, C. A. (1965). Epilepsia (Amst.), 6, 167 .
Golbert, T. M., Sanz, C. J., Rose, H. D., and Leitschuh, T. H. (1967). f. Amer. med. Ass., 201, 99.

Hendrickse, R. G., and Sherman, P. M. (1966). Brit. med. F., 2, 860.

Lalji, D., Hosking, C. S., and Sutherland, J. M. (1967). Med. F. Aust., 1,542 .

Lombroso, C. T. (1966). Neurology (Minneap.), 16, 629.

Maspoli, M. (1967). Schweiz. med. Wschr., 97, 320.

Parsonage, M. J., and Norris, J. W. (1967). Brit. med. f., 3, 85.

Prensky, A. L., Raff, M. C., Moore, M. J., and Schwab, R. S. (1967) New Engl. 7. Med., 276, 779.

Sawyer, G. T., Webster, D. D., and Schut, L. J. (1968). F. Amer. med. Ass., 203, 913.

\section{Preliminary Communications}

\section{Papillary Necrosis in Experimental Analgesic Nephropathy}

Brit. med. F., 1969, 1, 161-162

Cummary : A proprietary aspirin, phenacetin, and caffeine preparation given to rats in a dose equivalent to that taken by patients with analgesic nephropathy produced papillary necrosis in $55 \%$. There was a higher incidence in rats deprived of fluids overnight.

Papillary necrosis was not noted in rats receiving twice as much phenacetin.

These findings support the argument that phenacetin should not be singled out as the substance responsible for analgesic nephropathy in man.

\section{INTRODUCTION}

Animal experiments have usually failed to show any convincing lesions in the kidney after prolonged administration of analgesics (Shelley, 1967). Papillary necrosis is the characteristic lesion in analgesic nephropathy in man (Kincaid-Smith, 1967a), and this paper reports the occurrence of papillary necrosis in a high percentage of rats receiving a proprietary aspirin, phenacetin, and caffeine (A.P.C.) mixture. Papillary necrosis was not noted in rats receiving twice as much phenacetin as that contained in the A.P.C. mixture.

\section{MATERIALS AND MethodS}

Wistar rats weighing $150 \mathrm{~g}$. received by gavage on five days each week phenacetin $500 \mathrm{mg} . / \mathrm{kg} /$ day or a proprietary analgesic mixture containing phenacetin $210 \mathrm{mg}$. $/ \mathrm{kg}$./day, aspirin 210 $\mathrm{mg} . / \mathrm{kg}$./day, and caffeine $80 \mathrm{mg} . / \mathrm{kg}$./day. A control group did not receive drugs. Half the animals in each group were deprived of fluids overnight (see Table). This produced a striking rise in urine osmolarity and may thus have potentiated any toxic effect of the analgesics on the medulla.

Findings in animals killed at three months and five months have been reported (Kincaid-Smith et al., 1968). It had been planned to continue the experiment for a year, but very heavy losses in the A.P.C. group after six months made it necessary to kill all the remaining animals between six and nine months.

\section{RESULTS}

Ten out of 18 rats receiving the proprietary A.P.C. mixture for more than six months developed papillary necrosis (see Table). A further 10 rats receiving A.P.C. died over this period but were not satisfactory for examination owing to cannibalism and autolysis. Papillary necrosis was noted in six $(75 \%)$ out of eight rats deprived of fluids overnight and in 4 $(40 \%)$ out of 10 rats with continuous access to water. Papillary necrosis was not noted in the control group (28) or in rats receiving phenacetin alone $(27)$ in a dose of $500 \mathrm{mg} . / \mathrm{kg}$./day.

\begin{tabular}{|c|c|c|c|c|c|c|}
\hline \multicolumn{7}{|c|}{ Table of Results } \\
\hline & \multicolumn{2}{|c|}{ Control } & \multicolumn{2}{|c|}{ Phenacetin } & \multicolumn{2}{|c|}{ A.P.C. } \\
\hline & $\begin{array}{c}\text { Free } \\
\text { Fluid }\end{array}$ & $\begin{array}{c}\text { Restricted } \\
\text { Fluid }\end{array}$ & $\begin{array}{c}\text { Free } \\
\text { Fluid }\end{array}$ & $\begin{array}{c}\text { Restricted } \\
\text { Fluid }\end{array}$ & $\begin{array}{c}\text { Free } \\
\text { Fluid }\end{array}$ & $\begin{array}{c}\text { Restricted } \\
\text { Fluid }\end{array}$ \\
\hline $\begin{array}{l}\text { No. of rats killed } \\
6-9 \text { months. } \\
\text { Papillary necrosis }\end{array}$ & $\begin{array}{r}14 \\
0\end{array}$ & $\begin{array}{r}14 \\
0\end{array}$ & $\begin{array}{r}14 \\
0\end{array}$ & $\begin{array}{c}13^{*} \\
0\end{array}$ & $\underset{4}{10 \dagger}$ & $\begin{array}{l}8 \ddagger \\
6\end{array}$ \\
\hline
\end{tabular}

Four animals with papillary necrosis showed cortical scars, and these could be seen in serial sections to result from atrophy of tubules which were obstructed in the papillary lesion. The cortex was normal in animals with normal papillae except for a patchy increase in lipofuchsin pigment in tubular cells in some animals receiving phenacetin and A.P.C.

Some abnormalities were noted in the papillae in rats receiving phenacetin alone; these included patchy cast formation and an unidentified pigmented substance in the interstitium of the medulla in a few animals. The lesions in the vasa recta noted in the early months of this experiment (Kincaid-Smith et al., 1968) did not seem to advance between six and nine months and no definite thrombosis or occlusion of these vessels was noted. Platelets were, however, noted adhering to the endothelium in some abnormal vessels.

\section{Discussion}

We have confirmed the high incidence of papillary necrosis in rats given a proprietary A.P.C. mixture for between six and nine months and also the pathogenesis of the renal lesions in these animals. Papillary necrosis precedes cortical scars, and these result from atrophy of tubules obstructed by the necrosis in the papilla (Abrahams and Levin, 1967 ; Kincaid-Smith et al., 1968). This is a similar pathogenesis to that described in analgesic nephropathy in man (Kincaid-Smith, 1967a).

The dose of A.P.C. mixture given to the rats was equivalent in $\mathrm{mg} . / \mathrm{kg}$./day to that taken by some patients with analgesic nephropathy.

Phenacetin has been generally assumed to be the cause of renal damage in analgesic nephropathy in man, though evidence against phenacetin depends mainly on the fact that it is present in most of the mixtures said to cause renal damage. Recently attention has been drawn to the lack of direct evidence against 